\title{
Las emociones y la vida moral: una lectura desde la teoría cognitivo-evaluadora de Martha Nussbaum
}

\author{
IVÁN PINEDO CANTILLO* \\ Universidad Nacional de Colombia (Colombia) \\ iapinedoc@unal.edu.co \\ JAIME YÁÑEZ CANAL** \\ Universidad Nacional de Colombia (Colombia) \\ jyanezc@unal.edu.co
}

\begin{abstract}
Resumen
En la filosofía y la psicología moral existe una discusión actualmente de vital importancia, esto es la relación entre moral y emociones. Después de una larga tradición de pensamiento en donde los procesos de justificación moral se asociaron con el valor normativo de la razón, hoy en día asistimos a una nueva orientación que defiende la integración de aspectos cognitivos y emocionales dentro del análisis de la acción moral y los compromisos ciudadanos. En este contexto, Martha Nussbaum, con su teoría cognitivo-evaluadora de las emociones, aporta una original reflexión ética centrada en lo que ha denominado el juicio eudaimonista ligado al florecimiento de la persona y la comprensión de una vida humana buena. Esta visión posibilita entender las emociones como advertidores de vulnerabilidad, sufrimiento y dignidad humana menoscabada, en momentos en que miles de hombres y mujeres se sumergen en lo infrahumano.
\end{abstract}

Palabras clave: Emociones, cognición, moral, vulnerabilidad, dignidad humana.

\section{Emotions and moral life: a reading from the cognitive-evaluator theory of Martha Nussbaum}

\begin{abstract}
In moral philosophy and psychology there is currently discussion of vital importance, this is the relationship between morality and emotions. After a long tradition of thought in which the processes of moral justification were associated with the normative value of reason, today we are witnessing a new orientation that defends the integration of cognitive and emotional aspects within the analysis of moral action and citizen commitments. In this context, Martha Nussbaum, with her cognitive appraisal theory of emotions, contributes an original ethical reflection focused on what has been called the eudaimonist judgment linked to the flowering of the person and understanding of a good human life. This vision makes it possible to understand the emotions as warners of vulnerability, suffering and human dignity undermined, at a time when thousands of men and women are immersed in the subbuman.
\end{abstract}

Keywords: Emotions, cognition, moral, vulnerability, buman dignity.

Magister en Filosofía, candidato a Doctor en Filosofía. Miembro del grupo de investigación: "Estudios sobre el desarrollo socio-moral”, Facultad de Ciencias Humanas, Departamento de Psicología, Universidad Nacional de Colombia.

* Doctor en Filosofía y Psicólogo. Profesor Asociado del Departamento de Psicología, Facultad de Ciencias Humanas, Universidad Nacional de Colombia. Grupo de investigación: "Estudios sobre el desarrollo socio-moral".

Recibido: 7/Noviembre/2016 - Aceptado: 9/Enero/2017 


\section{Introducción}

En las últimas décadas Martha Nussbaum es considerada una de las pensadoras más notables que se ha convertido en un referente para todos aquellos interesados en comprender las teorías cognitivas de la emoción y sus posibles aplicaciones en diferentes campos de la vida humana: política, educación, ética, comprensiones sobre ciudadanía y relaciones interpersonales, entre otros. En Paisajes del pensamiento: la inteligencia de las emociones, Nussbaum (2008) expone su visión cognitivo-evaluadora de las emociones, la cual es el resultado de una relectura de los planteamientos estoicos sobre las emociones entendidas como juicios de valor en combinación con una recuperación del concepto de endaimonía propio de la tradición aristotélica. En el pensamiento de Nussbaum los juicios valorativos juegan un rol esencial para que se produzca la reacción emocional y es a través de ellos como podemos encontrar una conexión entre emociones y vida moral. Los juicios son propiedades de lo emocional que podemos rastrear en diversos textos antiguos, pero que se han recuperado de manera más explícita y con mayor elaboración conceptual en la psicología y filosofía contemporánea de las emociones que se viene desarrollando desde finales del siglo pasado, cuando se dio el giro de las teorías fisiológicas a las teorías cognitivas de la emoción.

Autores como Arnold (1960), Lazarus (1996), Frijda (1987) y Solomon (2003) son los antecesores contemporáneos en los cuales se nutre Nussbaum para elaborar su propuesta filosófica cognitivo-evaluadora de las emociones. La otra parte de su teoría es heredera del mundo antiguo. En este contexto, el presente artículo pretende analizar algunos puntos claves del pensamiento de Nussbaum en torno a la relación entre emociones y vida moral, recorriendo ideas relevantes de la filósofa norteamericana como la capacidad del repertorio emocional para identificar situaciones de sufrimiento, vulnerabilidad y dignidad humana menoscabada tanto en individuos como en comunidades sometidas a la estigmatización social y la marginación.

Para comprender la originalidad de las posturas teóricas de Nussbaum debemos, pues, retomar algunas ideas en las cuales se enraíza su pensamiento de tal forma que, a partir de sus presupuestos, podamos luego reconocer el alcance y potencial moral de las emociones tanto en la vida individual como en la deliberación pública. 


\section{La tradición estoica en la teoría de las emociones de Nussbaum}

Se atribuye a Crisipo un viejo texto Sobre las pasiones que recoge diversas enseñanzas estoicas al respecto; este es un documento recuperado doxográficamente por Diógenes Laercio y otros autores como Galeno que nos da cuenta sobre cierta concepción dicotómica entre razón y emoción característica del mundo antiguo. Según Crisipo la pasión es un impulso que excede y desobedece a la razón, es decir, un movimiento irracional del alma en contra de la naturaleza; de ahí la vieja frase estoica: "aun cuando tengo pensamiento la pasión me fuerza". Esta idea es consecuente con la visión antigua de las pasiones: algo que "se padece" (Pathos), un movimiento interior que sobreviene sin la intervención de la voluntad y afecta nuestro pensamiento. Según la doctrina estoica las emociones tienen que ver con la forma en que se valoran objetos y situaciones con una valencia buena o mala y en relación con un tiempo presente o futuro (Knuuttila, 2004). Si es sobre un objeto o acontecimiento del presente, el juicio implicará emociones de placer (bedonê) o dolor (lupé), y si es acerca del futuro implicará una emoción de apetito (epithumia) o miedo (phobos).

Crisipo, por tanto, introduce la idea de las emociones como un tipo de creencia (doxa) o juicio evaluativo (krisis) que determina una propiedad buena o mala en los objetos: esto es X, y X es bueno o malo y por tanto es apropiado reaccionar a X de determinada manera emocional. En este punto lo que más resalta de la doctrina estoica es la idea de creencia o juicio entendido como el asentimiento a una apariencia. Se trata de un proceso en dos momentos: primero tenemos un evento que llama nuestra atención y crea una impresión, es decir, vemos la situación de determinada manera, luego aceptamos o abrazamos esa representación o apariencia como verdadera, nos comprometemos con ella y hacemos un juicio que genera una emoción (Nussbaum, 2003).

$\mathrm{Al}$ concebir a las emociones de esta manera, los estoicos consideran que los padres, las personas que nos cuidan durante la infancia, la cultura a la que pertenecemos y los pedagogos, pueden generarnos falsas creencias y prejuicios que influyen en la aparición de estados emocionales descontrolados. Esta es la razón por la que Crisipo llega a pensar que las emociones son desobedientes a la razón y contrarias a la naturaleza al dársele a los objetos y bienes externos (personas, dinero, fama, posición social, belleza, etc.) un peso o valor más allá del apropiado, esto es un juicio impulsivo acerca de cosas presentes o futuras: los juicios emocionales son errores del pensamiento, juicios falsos o concepciones inadecuadas acerca de la realidad que desencadenan un cúmulo de estados que ciegan y desorientan a la recta razón (Graver, 2007). 
El dolor, por ejemplo, diluye al alma en la aflicción y no deja ver con claridad la realidad presente, por eso solo el sabio estoico es dueño de sí manteniendo la serenidad del alma y el autocontrol. El hombre sabio es aquel que comprende lo que acontece y lo acepta: reconoce el orden cósmico, no se deja llevar por las valoraciones iniciales desproporcionadas y se resigna ante lo que es necesario e inevitable; si razonamos correctamente, concluiremos que lo mejor es aceptar el orden natural (Fitzgerald, 2008). En este sentido, en el estoicismo hay lugar para la libertad. El hombre auténticamente libre no permite que ninguna pasión o deseo perturbe la aceptación del orden cósmico; esta imperturbabilidad es la virtud de los fuertes. No es extraño, por tanto, que los estoicos abogaran por una extirpación del mundo emocional bajo la idea de Ataraxia o imperturbabilidad del alma y Apathia o indiferencia frente al placer y dolor (Nussbaum, 2003). Epicteto resume esta desconfianza alrededor de las pasiones en la máxima: "vigílate como un enemigo al acecho". El sabio estoico reconoce que los juicios con los que se identifican las pasiones son falsos, pues las cosas externas no tienen tanto valor, en realidad carecen por completo de valor ético intrínseco, por tal motivo tiene la capacidad de sobreponerse a ese cúmulo de creencias erróneas denominadas pasiones tratando de llevar una vida serena frente a todo lo que acontece en este mundo.

A tenor de lo dicho, Nussbaum retoma de los estoicos la noción del juicio como asentimiento a la apariencia de las cosas, aspecto que conforma la dimensión evaluativa de las emociones: mis emociones revelan si contemplo el mundo, o un aspecto del mismo, como amenazador o acogedor, placentero o doloroso, deplorable o consolador, o de cualquier otra manera. Pero Nussbaum orientará este punto de vista estoico en otra dirección al incluir la perspectiva aristotélica del juicio eudamonista vinculado con el florecimiento de la persona. Este es un aspecto que será de gran relevancia dentro de la concepción cognitiva que Nussbaum desarrolla en torno a las emociones.

\section{Huellas de la teoría aristotélica de las emociones}

Aristóteles no desarrolló una teoría completa y sistemática de las emociones, pero dejó diversos planteamientos al respecto en la Ética Nicomaquea, Ética Eudemia, Retórica y Del alma. De estos textos Nussbaum retoma algunos fragmentos para nutrir su propia visión cognitivo-evaluadora de las emociones. En sus escritos, Aristóteles sostiene que las pasiones en general van acompañadas de placer y/o dolor, las cuales conducen a cierta alteración o cambio corporal: "llamo pasiones al deseo, la cólera, el temor, la envidia, la alegría, el odio, la añoranza, la emulación, la piedad, y en general a todas las afecciones a las que son concomitantes el placer o la pena" 
(Aristóteles, 2010: 1105b20-23). Las emociones de vergüenza, temor, envidia e indignación son afecciones dolorosas. Por ejemplo, la vergüenza produce dolor por la pérdida de la buena reputación en la comunidad; sólo los desvergonzados serían indiferentes a esta situación (Knuuttila, 2004).

Si bien Aristóteles reconoce la dimensión física o corporal de las emociones: temblor, calor en la sangre, sudor, frío, etc., en diversos fragmentos de su obra se centra en una interpretación cognitivista en donde concede un lugar preponderante a la relación entre creencias y emociones, asunto que será de especial relevancia para la teoría de Nussbaum. La idea fundamental que defiende Aristóteles es que las emociones están asociadas con ciertas creencias (doxal) y juicios (bypolepsis): la creencia de que hemos sido objeto de un agravio inmerecido, por ejemplo, excita nuestra ira (Aristóteles, 1990: 1378a30), y la creencia de que el sufrimiento de alguien es inmerecido despierta nuestra compasión (Aristóteles, 1990: 1385b13-19). Si tenemos la convicción de que alguien que conocemos guarda algo perverso en su interior, esta creencia obstaculizará la aparición de la piedad y probablemente provocará ira o indignación. Cuando creemos que algo es temible o dañino, inmediatamente padecemos en nuestro cuerpo los síntomas del miedo (Aristóteles, 1988: 427b21-24).

El cambio de creencias puede traer entonces un cambio en las emociones. Si caemos en cuenta que las arañas que caminan por la casa no son venenosas, podemos llegar a experimentar serenidad o indiferencia cuando las vemos, pues nuestra creencia ha sido modificada al comprender que no hay ninguna sustancia nociva en esos insectos. De igual manera la cólera que sentimos contra alguien puede disminuir o desaparecer si caemos en cuenta de que, en realidad, no había ninguna injuria por parte de esa persona, o que las expresiones que en algún momento utilizó en el diálogo no tenían ninguna intención explícita de ofendernos. Sin embargo, conviene anotar que en diversas emociones la que conduce la afección es la phantasía o imaginación, que no es exactamente un juicio racional sino un tipo de representación distinta de las creencias (Knuuttila, 2004).

Con estas nociones previamente establecidas, Aristóteles nos invita a reconocer la importancia de las emociones en la comprensión moral. Las emociones, por ejemplo, pueden despertar el sentido de compasión al percatarnos del sufrimiento ajeno o del dolor inmerecido, también pueden provocar enojo cuando percibimos acciones contrarias a la virtud. Por este motivo, el estagirita se aleja de aquellas doctrinas que buscan la insensibilidad frente al placer y dolor (Apatheia) o las que proponen la imperturbabilidad (Ataraxia) como camino de vida; por el contrario, estas tendencias son consideradas una deficiencia humana y hasta un vicio (Aristóteles, 2010: 1104b24-25). No indignarse por la injusticia cometida al prójimo 
puede resultar una actitud servil propia de esclavos. El que no siente temor ante nada puede estar más cerca a la demencia que a la virtud.

En esta breve exposición se puede apreciar cómo Aristóteles comparte con los estoicos un componente cognitivo en las emociones, sin embargo, la orientación que propone es diferente. Para los estoicos las creencias asociadas a las pasiones afectan el buen desempeño de la razón y son un obstáculo para la excelencia humana, mientras para Aristóteles las emociones garantizan el respeto y la adecuada relación con los demás en el marco de la comunidad política, por eso están vinculadas a la vida virtuosa y la formación del carácter (Trueba, 2009).

Estos planteamientos llevan a Nussbaum a considerar las emociones como inteligentes: "Desde el punto de vista de Aristóteles las emociones no son fuerzas animales ciegas, sino partes inteligentes y discriminadoras de la personalidad, estrechamente relacionadas con creencias de cierta clase, y por tanto sensibles a modificaciones cognitivas" (Nussbaum, 1996a: 303). Esta racionalidad de las emociones en la Ética Nicomaquea se encuentra estrechamente vinculada con la idea de virtud entendida como búsqueda del término medio según el hombre prudente: las emociones deben ser adecuadas a los objetos y situaciones que las provocan y deben ser experimentadas de modo apropiado. Las pasiones, en tanto afecciones, no son dignas de elogio o censura, en tanto que sí lo son según la manera y las circunstancias en que son experimentadas por las personas (Aristóteles, 2010: 1105b31-110).

Estas ideas aristotélicas combinadas con algunas teorías contemporáneas de la emoción llevan a Nussbaum a considerar que las creencias son elementos constitutivos de las emociones a la vez que condiciones necesarias y suficientes para que éstas se den. La perspectiva que asume Nussbaum se aclara mediante el análisis de los aportes de las teorías cognitivas de la emoción desarrolladas en las últimas décadas.

\section{La influencia de las teorías cognitivas de la emoción en el pensa- miento de Nussbaum}

La idea según la cual las emociones son fuerzas irracionales separadas de la cognición y del juicio se fundamentan, desde una visión contemporánea, en las denominadas teorías fisiológicas, no cognitivas, de la emoción. Se atribuye a William James una de las primeras reflexiones realizadas al respecto en su célebre artículo "What is an emotion?" Publicado en la revista Mind de 1884. Según la teoría de James las emociones son percepciones de los cambios fisiológicos y viscerales que tienen lugar en el individuo tras confrontarse con un estímulo proveniente del medio ambiente. El modelo que seguía James para entender estas reacciones automáticas es el 
reflejo. Al igual que el reflejo rotular no demanda ninguna posibilidad de control por parte del individuo, las emociones deberían asemejarse a estas reacciones corporales. La percepción de la reacción fisiológica es, en esta concepción, el elemento central de la emoción: "Es imposible pensar qué tipo de emoción de temor, por ejemplo, quedaría si no estuvieran presentes ni la aceleración de los latidos del corazón, ni la respiración entrecortada, ni el temblor de los labios o la laxitud de los miembros, ni la carne de gallina, ni las contracciones de las vísceras" (Calhoun \& Solomon, 1989: 147).

A partir de James otros defensores de las teorías fisiológicas como Ekman \& Davidson (1994), Izard (1997), Prinz (2004) y LeDoux (1998), entre otros, han defendido la relevancia de las reacciones viscerales y la activación del sistema nervioso, tanto central como periférico, como condiciones fundamentales para la generación de un estado emocional.

En oposición a este reduccionismo fisiológico, y a visiones que desde la antigüedad concebían las emociones como movimientos irracionales o energías irreflexivas que simplemente manejan a las personas sin estar vinculadas a las formas en que ésta percibe o concibe el mundo, encontramos otro tipo de argumentos como los propuestos por Arnold (1960), Frijda, (1987), Lazarus (1996) y Solomon (2003; 2004) que afirman cómo el cambio físico en sí mismo no es suficiente para el surgimiento de la emoción. Para estos autores es necesario que entre la activación fisiológica y la emoción se dé la mediación de un proceso de evaluación cognitiva. Para Arnold este es el aspecto central que la teoría de James no explica satisfactoriamente: la idea según la cual tenemos la percepción de un objeto y luego cambios corporales que elicitan una emoción no aclara la conexión entre la percepción y la reacción corporal. Según Arnold (1960) falta una explicación de lo que allí sucede y es que la percepción del objeto está acompañada de una valoración (appraisal), la cual debe entenderse como un tipo de "juicio sentido", directo, inmediato, intuitivo (no equivalente a juicio intelectual o pensamiento racional, deliberado y consciente) de lo bueno o beneficioso que hay en una situación, o de lo malo o perjudicial que debe rechazarse y que, en consecuencia, provoca la reacción emocional. En este sentido, la nueva secuencia para desencadenar las emociones tal como proponen las teorías cognitivo-evaluativas es: Percepción - Appraisal - Emoción (Cornelius, 1996).

Si la valoración del evento es positiva o negativa generará un tipo de patrón psicológico igualmente positivo o negativo que se evidenciará en una expresión característica de una emoción; por ejemplo, en el miedo encontramos sudoración, latidos fuertes, piel de gallina, etc. En este caso el patrón implica la percepción de algo dañino o nocivo en el medio ambiente. Aunque la afección de entrada es corporal y está provocada por 
algo externo a nosotros, en el fondo de ella yace algún pensamiento, juicio o creencia relativa a lo que acabamos de percibir, y que nos lo señala como algo temible o digno de atención. Una teoría cognitiva de la emoción es, por consiguiente, aquella que incluye algún aspecto del pensamiento, usualmente una creencia o un juicio, central para el concepto de emoción, de esta forma se aleja la emoción de la tendencia al irracionalismo señalando su capacidad para informarnos y orientarnos sobre cierta parte del mundo con la cual tenemos relación, a la vez que es una motivación para nuestras acciones (Lyons, 1993).

Los filósofos y psicólogos defensores de la teoría cognitivo-evaluativa de las emociones sostienen la tesis según la cual la cognición y la emoción son interdependientes. El fondo de las emociones es básicamente racional, por tanto, no se puede establecer la frontera tradicional entre razón y emoción que es una herencia del antiguo dualismo entre razón y pasión que dominó buena parte de la historia de la filosofía. Si se entiende la cognición como la manera en como un organismo organiza o procesa los estímulos o la información del ambiente, entonces "las emociones también serían en algún sentido cogniciones, pues implican un procesamiento, consciente o inconsciente, de información" (Cabezas, 2014: 69). De hecho, lo original de esta propuesta consiste en diluir esta vieja dicotomía y ampliar el horizonte de reflexión más allá de las teorías del sentir y de las reacciones fisiológicas automáticas y reflejas. Las emociones son respuestas complejas de un individuo a los estímulos del entorno, y aunque implican reacciones fisiológicas, se caracterizan fundamentalmente por una valoración positiva o negativa (appraisal), de un objeto intencional (persona, cosa, acontecimiento o situación), y una tendencia a la acción según la evaluación realizada: objeto nocivo, benéfico o amenazador (Lyons, 1993).

\section{La teoría cognitivo-evaluadora de Nussbaum: neoestoicismo, neoaris totelismo y cognitivismo contemporáneo}

Teniendo en cuenta los anteriores presupuestos, Nussbaum asume su pensamiento sobre las emociones como un planteamiento neoestoico, pero cuestionará varias de las ideas de Crisipo y Séneca, particularmente la concepción de las emociones como juicios erróneos. Si las emociones son una clase de juicios o pensamientos por qué razón deben ser considerados necesariamente erróneos; por el contrario, plantea cómo en las emociones encontramos también un tipo de juicio en donde se atribuye valor positivo 
a cosas o situaciones: se trata de algo bueno porque encierra valor o importancia para mí. Las emociones siempre tienen un objeto intencional ${ }^{1}$, aunque se trate de un objeto vago, al cual investimos de valor y lo rodeamos de creencias ${ }^{2}$. Pero es una relación con el objeto que entraña cierta profundidad, una manera de ver que afecta la existencia del observador. Lo que Nussbaum (2008) concibe es una forma de percibir e interpretar, o dar valor, a los eventos del mundo. Tal es el caso de la aflicción que ella sintió por la muerte de su madre, asunto ampliamente tratado en Paisajes del pensamiento y que ayuda a introducir su teoría: la autora veía que alguien a quien amaba, o lo que es lo mismo, su objeto intencional, por siempre se iba, generando un estado emocional que cambiaba o agudizaba cada vez que contemplaba en ese cuerpo sin vida un sinnúmero de acontecimientos de su infancia, su pasado y su presente.

Esta valoración del objeto intencional de la emoción es lo que Nussbaum denomina un pensamiento evaluador endaimonista, un tipo de juicio ligado al florecimiento de la persona: el objeto de la emoción es visto como importante por algún papel que desempeña en la propia vida de la persona. El juicio endamonista indica que las emociones posibilitan ver el mundo desde el punto de vista de nuestros objetivos y proyectos. Las emociones se relacionan con algo que resulta relevante para nuestro bienestar, con las cosas a las que asignamos valor en el marco de lo que para nosotros significa una vida buena. Mis objetivos y fines, las cosas a las que atribuyo importancia también están ligadas al sentido de la vida, a nuestra condición existencial que nos permite reconocernos como seres que necesitamos de otros, y para los que es significativo nuestro acompañamiento y preocupación: "la forma fundamental de una emoción de fondo siempre es el amor

1 El término "objeto intencional" remite a la tesis propuesta por Brentano (2002; 1942) en sus textos El origen del conocimiento moral y en Psicología, en donde el filósofo plantea cómo la conciencia tiene una estructura intencional, es decir, los actos de conciencia se dirigen a objetos. Cualquier persona que piensa, piensa en algo, y cualquier persona que tiene miedo, tiene miedo por algo. Es en este contexto donde se afirma que las emociones son actos intencionales orientados por valores.

2 Para Solomon (2003), bajo la categoría de creencias encontramos diferentes formas de pensamiento: convicciones, dudas, suposiciones, especulaciones, conjeturas, sobre las cuales está fundada una emoción. Camila está enojada con el profesor porque cree que tiene preferencias con otros alumnos, mientras es muy distante y severo con ella; por consiguiente la emoción de enojo o resentimiento va de la mano con creencias reconocidas sobre el trato injusto. Así sucederá con otras emociones como la tristeza, la indignación o el asco. En este sentido algunos teóricos cognitivos sostienen que cada tipo de emoción está basada en un tipo particular de pensamiento. Tener una emoción es, en parte, creer que el mundo se presenta de cierta forma: el mundo aparece a los ojos de Camila de cierto modo; en su caso bajo la forma de acciones de injusticia o desigualdad. A los ojos del celoso, el ser amado aparece como un sujeto que desea traicionar su amor.

VERITAS, No 36 (Abril 2017) 
o el apego a alguien considerado muy importante para el florecimiento propio, junto con alguna creencia general que signifique que el bienestar de esa persona no se encuentra plenamente bajo nuestro control" (Nussbaum, 2008: 98).

El juicio evaluador eudaimonista nos remite a su sentido aristotélico antiguo $^{3}$, es decir, a aquello que el ser humano entiende por una vida humana buena y plena e implica las personas y situaciones a las cuales el sujeto atribuye un valor intrínseco. En el juicio eudaimonista se concede valor a las personas, acciones y relaciones humanas no por la relación instrumental que puedan guardar con la satisfacción del agente, lo cual es muy utilitarista, sino porque "tienen que ver conmigo mismo, con lo mío, con mis planes y objetivos, con lo que es importante en mi propia concepción de lo que significa vivir bien" (Nussbaum, 2008: 55). Es claro, entonces, que las emociones contienen en su interior una concepción del valor o de la importancia del objeto: es inherente a las emociones el valor con que se ha investido determinado objeto.

Ahora bien, en el juicio eudaimonista que estamos considerando conviene aclarar dos niveles: juicios evaluativos de fondo y juicios evaluativos de situación. Por ejemplo, frente a la experiencia de la muerte de un ser querido permanece un juicio de fondo sobre la mortalidad propia y la negatividad que la muerte tiene para los fines y objetivos de una persona. Los juicios de fondo son aquellos en los cuales se reconoce un enorme valor a personas y situaciones que perduran largo tiempo en el tejido de la propia vida y resultan cruciales para explicar nuestras acciones en diferentes momentos de la existencia. Los juicios de situación están vinculados a momentos específicos y experiencias directas con personas y acontecimientos. Tal es el caso de las emociones que pueden surgir al presenciar una injusticia social. Es probable que, en general, un sujeto no experimente

3 Para Aristóteles la virtud del hombre es el modo de ser por el cual el hombre se hace bueno y por el que realiza bien su función propia (2010: 1106a22-24). La virtud es la disposición que resulta de los mejores movimientos del alma, y es también la fuente de las mejores acciones y pasiones de esta (2001: 1220a30-42). La auténtica felicidad (eudaimonía) radica en el vivir y el actuar de acuerdo con la virtud; la felicidad es el bien que, cuando lo poseemos, nos hace independientes, y el hombre es independiente cuando posee todo lo necesario para su felicidad. La actividad del hombre bueno, es por sí misma buena, agradable y feliz (2001: 1219a27-35). En la Ética Eudemia Aristóteles relaciona las acciones con la virtud y la felicidad así: "las acciones de acuerdo con la virtud serán por sí mismas agradables. Y también serán buenas y hermosas, y ambas cosas en sumo grado, si el hombre virtuoso juzga rectamente acerca de todo esto, y juzga como ya hemos dicho. La felicidad, por consiguiente es lo mejor, lo más hermoso y lo más agradable...todas ellas pertenecen a las actividades mejores, y la mejor de todas estas decimos que es la felicidad" (2001: 1099a20-31). 
indignación por los problemas sociales del país, pero al toparse directamente con niños desnutridos, a causa de la grave corrupción política que desvía los dineros públicos destinados a su seguridad, puede sentir ira e indignación (Nussbaum, 2008). También es muy probable que se dé una mezcla de juicios de fondo y juicios de situación. Por ejemplo, si una persona desde muy joven ha experimentado indignación por variadas situaciones de injusticia, sea en el colegio, en la universidad, o en el trabajo, y si esta percepción se ha acompañado de un compromiso activo en protestas sociales, es muy posible que sea más sensible y más propenso a demostrar su inconformidad en un campo amplio de desigualdades sociales.

También Nussbaum nos invita a considerar otros factores que influyen en la concepción cognitivo-evaluadora, como lo es la presencia de la imaginación. Con frecuencia, junto con la importancia que le he conferido a determinado objeto, la imaginación entra en juego aportando más de lo que los pensamientos eudaimonistas proporcionan por sí solos. Por ejemplo, frente a la muerte de un ser querido, los detalles que trae la imaginación desde el pasado le dan densidad e intensidad a la experiencia emocional. Esto lo resume Nusssbaum diciendo: "las emociones humanas son modeladas por el hecho de que somos criaturas perceptivas: su rica textura se origina en nuestras capacidades sensoriales" (Nussbaum, 2008: 89).

En este mismo orden de ideas, las emociones están vinculadas a las creencias del sujeto, ya sean actuales o pasadas, verdaderas o falsas, justificadas o injustificadas. Por ejemplo, si creo que Juan ha muerto en su expedición al Everest, seguramente sentiré gran aflicción. Pero si en realidad Juan está de regreso, y feliz por haber conquistado sus metas, mi emoción sería inapropiada, porque estoy afligido por una falsa creencia. La emoción es sincera, pero descansa en una creencia falsa. En este contexto Nussbaum considera que las emociones cesan cuando se modifican las creencias relevantes sobre el objeto y su valor. Como afirman otras teorías cognitivas de la emoción en Paisajes del pensamiento se comparte la idea de que las emociones pueden modificarse por un cambio en la forma en que se evalúan los objetos, pues son maneras de mirar las cosas cargadas de valor.

\section{El potencial moral de las emociones como advertidoras de daño, sufrimiento y dignidad humana menoscabada}

Para Nussbaum las emociones son juicios, pero no inertes, pues debido a su contenido evaluativo poseen una íntima conexión con la motivación. Este aspecto da paso a la amplia reflexión que expone la autora en torno al potencial que poseen las emociones en la deliberación moral al ser advertidoras de vulnerabilidad y dignidad humana menoscabada: las 
emociones desempeñan un papel en la percepción del daño moral y nos proveen una serie de motivos para actuar.

El concepto de vulnerabilidad es una idea central para comprender la dimensión ética del pensamiento de Nussbaum. Aristóteles (2010: 1095a19-20) afirma que vivir bien y actuar bien son lo mismo que la endaimonía, pero en esta búsqueda del buen vivir nos descubrimos como seres esencialmente vulnerables o frágiles frente a un sinnúmero de circunstancias exteriores que dificultan o contaminan la actividad buena y la excelencia humana. Aspiramos a lo largo de nuestra existencia a alcanzar una forma de vida autosuficiente, racional, que nos mantenga a salvo de la fortuna, pero la realidad concreta es todo lo contrario: la condición humana, y por tanto, la búsqueda de una vida buena, están sometidas a la contingencia, lo mudable e inesperado, lo que se escapa a nuestro control racional e incluso a nuestra capacidad de acción. En este contexto, se entiende por fortuna "lo que no le ocurre al ser humano por su propia intervención activa, sino lo que simplemente le sucede, en oposición a lo que hace" (Nussbaum, 1995: 31). Esta situación existencial de estar a la deriva de la fortuna es lo que hace vulnerable la vida humana buena y, por tanto, su florecimiento.

La fortuna trae circunstancias que privan, limitan o entorpecen la búsqueda de la excelencia humana, también afectan el carácter de la persona y conducen a la pregunta de fondo ¿cómo se puede decir que vive bien un individuo sometido al ultraje, la tortura, el hambre, las penurias y la discriminación? Esta continua exposición a situaciones dominadas por la fortuna lleva a Nussbaum a defender la idea según la cual el agente moral es un ser débil, expuesto al sufrimiento inmerecido, sometido a la inseguridad y puede ser dañado gravemente en su florecimiento al no ser reconocido por otros en su dignidad.

La vulnerabilidad es un concepto que recoge diversas características de la condición humana lábil y en palabras de Nussbaum las emociones "son respuestas a las áreas de vulnerabilidad, en las que registramos los perjuicios que sufrimos, que podríamos sufrir, o que por suerte no padecemos" (Nussbaum, 2006: 19). Los dioses, por el contrario, no están expuestos a esta condición porque son invulnerables al sufrimiento y totalmente autosuficientes; tales seres no tendrían ningún motivo para temer, porque nada que pudiera sucederles sería realmente malo. Una forma de existencia así es justamente la que plantean los estoicos al proponer una existencia casi invulnerable a las vicisitudes de esta vida, una forma de anulación de los vínculos con este mundo, en donde hay alegría y también mucho dolor (Nussbaum, 2003). La dificultad radica en que en el estoicismo esa búsqueda de la imperturbabilidad fácilmente puede conducir a la indiferencia, la desconsideración y una forma de deshumanización. 
La vida de los reyes y poderosos, tanto en la antigüedad como en la actualidad, puede dar cuenta de ese tipo de desconocimiento de lo humano, que puede conducir a un tipo de daño social, al generar sensaciones de invulnerabilidad por el poder del dinero, los lujos y las comodidades. Bajo las ideas de invulnerabilidad se pueden cometer los peores desmanes al no reconocer un rostro humano en el que nos rodea. Por eso durante mucho tiempo los reyes se movieron bajo la premisa de superioridad que los hacía pensar en "no contar nunca con ser humanos".

Pero la realidad de aquellos que no nos consideramos reyes todopoderosos es que somos individuos frágiles, expuestos a la enfermedad, al sufrimiento y a la muerte. Pero también somos muy desvalidos frente a la posibilidad de ser víctimas del mal ocasionado por otros individuos, de ser sometidos a tratos inhumanos, humillantes, violentos y degradantes: tenemos una misma vulnerabilidad y mortalidad. Este es el primer factor que nos hace iguales como humanos. Siendo esto así, las emociones de compasión, pesar, temor e ira son recordatorios esenciales y valiosos de nuestra condición común de humanidad y por lo mismo son advertidores que indican cuándo a nuestro alrededor hay sufrimiento y cuándo la dignidad humana ha sido menoscabada por la acción de otras personas.

\section{La compasión y la advertencia de sufrimiento}

La compasión es una emoción que posee un potencial relevante para la reflexión ética porque va asociada a la deliberación humana de cómo vivir bien reconociendo la fragilidad, la reciprocidad y la indulgencia. También es una emoción vinculada con la acción moral en donde se ponen en juego la conciencia por medio de juicios, opciones, decisiones y compromisos que dan cuenta de los principios y fines que orientan a la persona, y que son capaces de humanizar la realidad al traducirse en obras para los demás. Por esta razón la compasión es en el pensamiento de Nussbaum (1996b) la gran protección que nos queda frente a la vulnerabilidad que nos circunda por todas partes.

Siguiendo las ideas aristotélicas, Nussbaum (1996b) comprende la compasión como una emoción dolorosa dirigida al infortunio o al sufrimiento de otra persona (Aristóteles, 1990: 1385b13). Al concebirla así, el primer requisito cognitivo que estructura la compasión es una creencia o una evaluación según la cual el sufrimiento de otro ser humano es grave, inmerecido y no trivial. Aquí entra nuevamente la concepción de juicio eudaimonista o de florecimiento de la persona. Se trata de aprehender que hay ciertas circunstancias de la vida que no provocan una molestia superficial, sino que obstaculizan la existencia completa de un individuo hasta generar un profundo dolor. 
Los sufrimientos del ser humano son múltiples y de diversa intensidad. Quizá los más conocidos y extremadamente difíciles de afrontar son los provenientes de la finitud y caducidad de nuestro cuerpo. Las enfermedades antiguas y nuevas hacen descender al hombre a un nivel supremamente bajo de su ser, no se trata de una mera incomodidad física, sino una condición que afecta el sentido de todo lo que hacemos. Pero también tenemos los sufrimientos de carácter psicológico y social. La humillación experimentada por ser una minoría, por la orientación sexual, por la etnia o las condiciones de miseria que llevan al hambre, el maltrato o la soledad extrema, son tan solo una pequeña lista de lo que un ser humano puede experimentar en un corto o largo periodo de su vida. Los efectos, en definitiva, son similares: una punzante agonía de dolor que limita y amenaza por todos lados nuestra existencia concreta.

Para Nussbaum, la compasión es la forma que tiene nuestra especie de ligar el bien de los otros a la estructura fundamentalmente endaimonista, no egoísta, de nuestra imaginación y de nuestras preocupaciones más intensas: "Para que se despierte la compasión se debe considerar el sufrimiento de otra persona como una parte significativa del propio esquema de objetivos y metas. Se deben tomar las penurias de otra persona como algo que afecta el propio florecimiento" (Nussbaum, 2008: 258).

Ahora bien, esta teoría defensora de la compasión como un tipo de juicio evaluativo no implica la idea de dar por buenos e importantes todos y cada uno de los tipos de necesidades y dependencias humanas. Incluso los detractores de la compasión ven con sospecha esta emoción porque puede orientar a las personas a la falta de esfuerzo y dedicación para alcanzar sus metas: los individuos llegan a sentir que hay otros que siempre se van a compadecer, por tanto no es necesaria la lucha y la fuerza de voluntad. Pero Nussbaum es consciente de esta posibilidad y ofrece otros filtros cognitivos para el juicio evaluativo de la compasión teniendo en cuenta tres principios: a) magnitud o gravedad de la situación; es decir, el reconocimiento de que tal situación es relevante para el florecimiento de la otra persona, o sea, afecta en profundidad el sentido de la vida del otro, sus posibilidades de realización, su dignidad como persona. No sentimos compasión porque el otro perdió en una fiesta llena de música y licor su celular de última generación y está triste; b) el juicio del inmerecimiento, la creencia de que la otra persona no merece tal sufrimiento. En este punto entra la idea de responsabilidad en las acciones; es decir, hay personas que de alguna manera buscan su dolor, por ejemplo, el aficionado al casino que perdió en la ruleta un montón de dinero quizá no sea el más adecuado para ser objeto de nuestra compasión; c) la creencia según la cual las posibilidades de la persona que experimenta la emoción son parecidas a las del que padece el sufrimiento (juicio de las posibilidades parecidas). Este 
punto tiene relación con la idea de lograr empatía, así sea imaginaria, con la situación del otro, "ponerse en sus zapatos" y pensar que ese otro podría ser yo en forma real o hipotética. Este aspecto es lo que Nussbaum (2008) denominará la "simpatía extendida", que puede ser tanto por las personas que me rodean, como por seres humanos distantes y que no conocemos: a mí también me podría suceder eso porque finalmente soy un ser humano vulnerable a la enfermedad, a la incertidumbre del azar y a la muerte.

Es importante aclarar que la idea de compasión que expone Nussbaum no se identifica o equipara con el sentimiento de lástima que surgió en la tradición cristiana bajo el concepto de "obras de misericordia de la Iglesia", lo cual muchas veces se reduce a despojarse de cierto dinero y ciertos objetos que ya no se desean tener para ayudar a los pobres. ${ }^{4} \mathrm{La}$ idea de Nussbaum es más profunda, más existencial y enraízada en su idea de florecimiento humano que nos invita a una preocupación auténtica por proteger el conjunto de potencialidades fundamentales del ser humano, que es necesario desarrollar para que un individuo alcance la plenitud de lo que implica ser persona. En este sentido la compasión tiene estrecho vínculo con lo que Aristóteles denomina en su Etica Nicomaquea una formación del carácter. El juicio evaluativo eudaimonista se forma, se educa en las personas y es un elemento supremamente importante para los ciudadanos de sociedades democráticas abiertas y pluralistas.

Los animales no humanos también dan cuenta de posibles emociones altruistas y de valoración del sufrimiento ajeno que pueden ser tenidas como nociones de referencia para lo que nosotros podemos hacer y alcanzar con un cultivo apropiado de emociones tanto a nivel individual como público. Las investigaciones de De Waal (1997) muestran cómo en los elefantes, perros y bonobos, existen acciones que indican una real preocupación por el indefenso. Un ejemplo paradigmático es el de un grupo de elefantes que, al atravesar una carrilera, uno de los miembros de la manada quedó atascado en la vía con riesgo de muerte por la aproximación del tren. Cinco miembros de la manada regresaron e intentaron con sus trompas sacarlo del atolladero. Acción que al no ser exitosa los condujo a hacer

$4 \quad$ La idea de Nussbaum está más cerca de las comprensiones exegéticas actuales del término compasión entendido como un "sentir con las entrañas", traducción del griego esplaginizomai (Davies, 2003): “Al ver a la gente, Jesús sintió compasión de ellos porque estaban cansados y abatidos, como ovejas que no tienen pastor". Esplagjnon es un término que hace alusión al vientre, intestinos, entrañas, corazón, es decir, las partes internas, de donde provienen las emociones más profundas; según las interpretaciones actuales ese era el sentimiento correcto de Jesús frente al pobre y desvalido. En este contexto resulta sugestivo para la reflexión sobre las emociones desarrollar un vínculo entre las ideas de Nussbaum y las orientaciones exegéticas contemporáneas.

VERITAS, No 36 (Abril 2017) 
un círculo alrededor del elefante caído intentando protegerlo. No pudieron salvarlo, por el contrario, el tren pasó veloz y los mató a todos pues nunca se separaron del herido. Historias como estas son analizadas en diferentes lugares del planeta por biólogos, filósofos evolucionistas, ecologistas y demás estudiosos del mundo animal que dan cuenta de un sentido altruista o de compasión/simpatía que hace a estos seres capaces de percibir el sufrimiento y la angustia de sus congéneres.

Aceptando ciertas similitudes con el comportamiento altruista de algunos animales, es claro para Nussbaum que la mayor elaboración cognitiva hace a los humanos capaces de entender otras formas de dolor y discriminación. El hombre posee creencias, ideas y representaciones que le permiten ponerse en el lugar y en la sensibilidad del otro, a pesar de que su malestar no se manifieste en formas emocionales observables.

La visión de Nussbaum sobre la compasión como virtud moral individual también tiene una dimensión pública y política que resulta muy alentadora para el momento presente. El juicio evaluativo en torno a la situación de sufrimiento inmerecido del otro es un asunto que supera las fronteras del yo, y expande su influencia a las instituciones públicas y a las comprensiones de ciudadanía en general. En este sentido, la compasión debe mover a los ciudadanos a movilizarse en pro de la humanidad sufriente, llámesele hoy en día refugiados, víctimas de la guerra, mujeres oprimidas, migrantes, minorías o cualquier otro grupo vulnerable que no tenga por sí mismo otras posibilidades para su crecimiento humano. Entendida así, la compasión es una motivación para el desarrollo de la conciencia moral y la acción virtuosa que busca el bien no solo a nivel personal sino público. Este es un asunto que nos vincula con la visión del liberalismo político de fuerte raigambre rawlsiano que hace parte del pensamiento de Nussbaum, pero por las condiciones de brevedad de este artículo dejaremos este análisis particular para otra ocasión ${ }^{5}$.

La situación de muchos niños desnutridos y sin educación es para Nussbaum un problema que debe preocupar a los demás seres humanos, puesto que allí está en juego el florecimiento de estas personas. Con hambre y sin educación las posibilidades de desarrollar todas las potencialidades humanas a nivel intelectual, biológico, social, comunicativo o estético se ven seriamente amenazadas. No es una cuestión sólo de percepción sino un hecho real y verificable que los niños, en esas condiciones, nunca podrán tener oportunidades de desarrollo como lo tienen aquellos que gozan de confort o tienen acceso a todos los bienes de la civilización.

En las concepciones liberales de justicia Nussbaum sigue los lineamientos de Amartya Sen y establece aspectos particulares dentro de la propuesta de las capacidades y el desarrollo humano (Nussbaum, 2007; 2012). 
La indiferencia y la "invisibilidad" de este tipo de personas sufrientes es lo más ajeno al paradigma de la compasión. Para Nussbaum la compasión es un tipo de lealtad a la humanidad en donde se reconoce que otros son vulnerables y que necesitan de nuestra asistencia más allá de su clase, género, raza o religión. La inclusión de las personas con discapacidad física y mental en las políticas públicas ocupa un lugar importante dentro de esta comprensión de la benevolencia que, más allá de la caridad, propone nuevas lecturas de la justicia social para corregir las deficiencias de un contractualismo clásico regido por principios netamente económicos (Nussbaum, 2007). Por tanto, la compasión debe mover a los ciudadanos a exigir a los gobiernos, instituciones y entidades con capacidad de decisión que actúen en favor de esas personas que como náufragos se hunden en sus necesidades apremiantes. Esto implica por tanto incluir una perspectiva compasiva en el derecho, las leyes y las instituciones públicas, más allá de lo que se espera que todo gobierno mínimamente haga por suplir las necesidades básicas de todos los ciudadanos (Nussbaum, 2014).

Las instituciones deben promover una educación inclusiva, que respete la pluralidad, la diferencia y que fundamentalmente abogue por los débiles. También se debe exigir y presionar a las entidades con poder legislativo para que creen leyes que protejan a los vulnerables. En este punto podemos comprender la teoría de la compasión de Nussbaum como una bisagra que une la esfera moral individual (agencia del individuo) con la esfera de justicia que es propia de lo político y lo legal.

En este punto de la reflexión podemos realizar una observación sobre la noción de ciudadanía que se desprende de la teoría cognitivo-evaluadora de Nussbaum. La idea que defiende la autora es una idea de ciudadanía compasiva, es decir, hombres y mujeres que en la sociedad se preocupan por lo que concierne a los demás, especialmente a los que por razones de injusticia social son más vulnerables y con mayor propensión a no poder florecer humanamente dadas sus condiciones de vida. La compasión, por consiguiente, como virtud característica de la nueva ciudadanía puede estar acompañada de otras emociones pertinentes como la indignación por el maltrato a los débiles y la desaprobación de situaciones de exclusión, desigualdad o negligencia por parte de las instituciones públicas que deberían hacerse cargo de aquellas circunstancias en donde se percibe el hundimiento de personas en lo infrahumano. La teoría de Nussbaum es, pues, un punto de referencia muy importante para establecer vínculos futuros entre emociones, moral y política. 


\section{La repugnancia como limitante de la humanidad compasiva}

Si la compasión es la emoción que nos vincula a un tipo de amor por los demás, la repugnancia divide y genera asco frente a lo diferente. El asco "hace peligrar los proyectos personales o nacionales que implican algún tipo de sacrificio altruista por el bien común, ya que divide la vida pública en grupos ordenados jerárquicamente que no deben coincidir entre sí" (Nussbaum, 2006: 255). Como bien lo analiza Nussbaum con mayor profundidad en El ocultamiento de lo humano, la repugnancia surge de la creencia en la propiedad contaminante de ciertos objetos que nos recuerdan nuestra naturaleza animal y nuestra mortalidad: fluidos, secreciones, viscosidades, desechos. No sólo los objetos nos dan asco, cuya manifestación más visible es el vómito, sino también la "historia social de los objetos", es decir, aquellas cosas con las cuales creemos que ese objeto estuvo en contacto. Desarrollamos la creencia que si entramos en contacto con ese objeto, y peor aún si lo ingerimos, su naturaleza degradada nos contaminará hasta lo más profundo, es decir, hasta nuestro yo o estructura mental.

Desde una perspectiva evolutiva sabemos que el asco tiene una función positiva: nos alerta sobre alimentos y objetos peligrosos para nuestra salud y bienestar. Pero desde un punto de vista político y social se convierte en la fuente principal de humillación hacia otros. De esta forma surge lo que Nussbaum denomina la repugnacia extendida y subordinación de grupos: extendemos hacia otros seres humanos la idea de que son elementos contaminantes que no deben estar cerca de nosotros. Lo primero que hace la repugnancia es generar una exacerbación de valores equivocados. Por ejemplo, frente al patriotismo, genera lo contrario que es la aversión y la división de clases, grupos y etnias. La repugnancia genera creencias que ciertas personas: homosexuales, afrodescendientes, pobres, discapacitados, entre otros, traen consigo la contaminación para nuestra "alma limpia" y, por tanto, la solución es la discriminación de esos grupos. La repugnancia, en perspectiva de Nussbaum, es anti liberal, anti democrática y anti pluralista. Es la emoción que antecede al odio y la humillación que ha sido causa de grandes males en la humanidad (Nussbaum, 2014).

La costumbre de los intocables en el sistema de castas de la India es un claro ejemplo de esta aberración. Fundamentados en la tradición religiosa que separa desde el origen a unos seres humanos de otros, los miembros de esta nación han marcado su existencia en una división jerárquica inamovible. Tocar a un intocable o a sus objetos es signo de contaminación, algo de ese individuo se ha mezclado en nuestro ser y es necesario una serie de rituales de purificación para volver a un estado "normal". Claro está que para muchos se trata de un asunto cultural, pero hoy en día 
se cuestiona hasta qué punto se debe permitir este sometimiento a la degradación humana fundamentados en tradiciones inequitativas, violentas y altamente nocivas para el florecimiento de las personas. La marginación, la humillación, la falta de educación y la pobreza como consecuencia de este desconocimiento de la vulnerabilidad humana no enriquece ni construye a nadie, por el contrario perpetúa dinámicas de exclusión que se siguen manteniendo equivocadamente bajo la cuestionable idea de "herencias culturales".

En su texto sobre Emociones politicas, nos dice Nussbaum, que Gandhi desde muy temprano captó ese mundo de asco y segregación propio de la India, por eso siempre procuró hacer gestos emocionales de inclusión, amor y generosidad hacia todos. El cuerpo mismo de Gandhi era una imagen de la justicia que se debía implantar en un mundo marcado por la segregación y la pobreza: su cuerpo fue protagonista de ingeniosas representaciones dramáticas de una construcción nacional jamás puesta en escena (Nussbaum, 2014). De hecho una de las victorias de esta nueva manera de pensar fue la prohibición, a nivel constitucional, de la ley de intocabilidad propia del hinduismo. Naturalmente hay conservadores que se resisten a esta novedad, pero la India que surgió del pensamiento de Tagore, Gandhi y Nehru es signo de una nueva humanidad que se está construyendo.

Junto a la repugnancia suele caminar la vergüenza, esa emoción que invita a estigmatizar los rostros de miles de seres humanos en virtud de su condición marginal, desposeída y frágil. Nussbaum (2006) en El ocultamiento de lo bumano habla de una historia natural de la vergüenza y la humillación como narrativa de las causas más profundas por las que las sociedades humanas, una y otra vez, buscan marcar los rostros de algunos de sus miembros, lo que conduce a vivir con una "identidad manchada". La vergüenza fundamentalmente busca hacer sentir a ciertos miembros de la comunidad como indignos de pertenecer a una colectividad, grupo o nación porque las personas en cuestión "son rastreras, no están a la par de otros en términos de dignidad humana" (Nussbaum, 2006: 241).

No son muy distinguibles las fronteras entre avergonzar y humillar; por lo general se avergüenza para provocar humillación o se humilla para provocar vergüenza. Lo cierto es que se estigmatiza a las personas como no humanas, no dignas, no capaces, no puras, no "normales", no limpias, como seres contaminantes que traen consigo algo degradante que es mejor mantener a distancia. Ejemplos hay muchos, pero siguiendo las ideas de Nussbaum, las minorías LGBTI, los afroamericanos, los discapacitados, los individuos que sufren alguna deformidad, los pobres, son casos de individuos vulnerables que fácilmente pueden ser presa de la estigmatización social que conduce a la vergüenza. Esta dinámica de denigración se vuelve 
más aguda cuando en el derecho y en las legislaciones se incluye el factor emocional de la repugnancia como criterio para tratar a ciertos individuos, normalmente delincuentes o transgresores de la ley, como seres que ya no tienen redención y que difícilmente merecen ser contados como pertenecientes al género humano.

En este punto de la argumentación resaltamos el papel que tiene la vía emocional como una herramienta para detectar daños morales. La presencia del asco y la vergüenza nos deben conducir a un rechazo y desaprobación por ser actitudes moralmente injustificables. Tal como concibe Nussbaum el juicio eudamonista, las emociones incluyen valoraciones acerca de cómo se ve una cosa o una persona y cómo se cree que su presencia puede afectar nuestros objetivos, planes y a nosotros mismos. Esto ya es relevante en un sentido moral pues relaciona directamente las emociones con la percepción de posibles daños.

La vergüenza tiene como efecto inmediato, en el individuo que la padece, la generación en su psique de un autoconvencimiento de inferioridad o de dignidad humana venida a menos que invita al ostracismo y la marginación. En estas circunstancias ya hay una advertencia de daños a seres frágiles que, en la mayoría de los casos, por su incapacidad física, por su condición de pobreza, su falta de educación o el simple hecho de pertenecer a una minoría estigmatizada no puede defenderse ni reaccionar frente a la poderosa fuerza que tiene la presión social. En muchos casos la indignación moral es la emoción apropiada que debe surgir como consecuencia de los abusos y de las amenazas al bienestar de grupos o individuos vulnerables.

Según Nussbaum esta anomalía de generar vergüenza está asociada al efecto de ver reflejada en los demás nuestra propia fragilidad y naturaleza finita. Por tanto, se tiene el impulso a rechazar de la vista, a través de la humillación pública, a quienes llevan la debilidad en su rostro. Repugnancia, asco, vergüenza y odio son los nombres de repertorios emocionales que están latentes en la sociedad o se materializan para menoscabar la dignidad humana.

\section{De lo individual a lo colectivo: el potencial moral de las emocio- nes en la deliberación pública}

Llegados a este punto del análisis migramos hacia el papel de las emociones en la vida pública. Nussbaum sostiene que las naciones cimentadas en el liberalismo están comprometidas con el desarrollo de unas emociones políticas que sostengan sus más preciados objetivos. En la Religión del hombre, texto ampliamente comentado por Nussbaum (2014) en Emociones políticas, nos dice la filósofa que Tagore ya prefiguraba una imagen de una 
sociedad donde imperaba el respeto interreligioso y la afirmación de ciertos principios compartidos que humanizan la vida social y crean las condiciones para el desarrollo de los proyectos de vida individuales. En la escuela que Tagore fundó en Santinikentan (India) los estudiantes podían cultivar emociones de compasión y simpatía extendidas anulando las viejas prácticas de intocabilidadad y asco que eran la expresión visible de la jerarquización de castas. Tagore, Gandhi y Nehru prefiguraban así una nueva India en donde se cultivaran emociones positivas cuyo centro era el ser humano y su condición vulnerable.

Siguiendo las ideas de la tradición liberal inaugurada por Rawls, Nussbaum considera que las sociedades aspiracionales, no perfectas, que buscan la justicia, presuponen unos principios propios del liberalismo político en donde el respeto a todos los ciudadanos implica una idea de nación que no construye sus principios políticos sobre ninguna doctrina religiosa o laica en particular. Para lograr esto el factor emocional resulta crucial pues posibilita la unión en lo fundamental, facilitando la diversidad en aquellas cosas que no son de incumbencia del Estado. Las emociones públicas son, por tanto, una fuente tanto de estabilidad para los principios políticos positivos como de motivación para hacerlos efectivos. En este sentido, los valores políticos centrales, como la igualdad racial y la libertad de expresión, por ejemplo, aparte de ser apoyados por la ley, son fortalecidos y fomentados por el cultivo de emociones de compasión y amor hacia todos los hombres que tienen igual derecho a habitar este mundo sin sufrimientos evitables por el Estado (Nussbaum, 2014).

En esta reflexión sobre las emociones y el Estado liberal, Nussbaum no desconoce el problema que, siguiendo la tradición de Kant, representa lo que el filósofo prusiano denominó el "mal radical": una tendencia universal en la naturaleza humana que orienta a los individuos y comunidades al abuso de otras personas (instrumentalización del ser humano). Para evitar, o al menos hacer soportable este "mal radical", Kant propone que los individuos tienen el deber de integrarse en un grupo que refuerce las predisposiciones positivas, para que estas se impongan a las negativas. Existen propensiones en los seres humanos a tener conductas competitivas, envidiosas y excluyentes que devienen en odio y en deseo de muerte para el otro. Esto es válido tanto a nivel individual como público: si permanecemos pasivos e indiferentes frente al papel de las emociones en la vida social, tarde o temprano vendrán individuos y grupos, que movidos por otros principios, pondrán en movimiento el repertorio emocional de las comunidades para suscitar violencia y discriminación contra los más vulnerables. Tal es el caso de la Alemania Nazi: primero se inició con pequeñas facciones movidas por la idea de grandeza y superioridad, luego se pasó a la acción política con discursos emotivos que afectaban a grandes 
masas, después el partido se tomó el poder e inició la dinámica de asco, vergüenza y humillación que todos conocemos.

Nussbaum comprende esta tendencia del "mal radical" y justamente propone el fomento de emociones políticas a través de ceremonias, monumentos, eventos y creaciones artísticas, como instrumentos para combatir esta orientación humana a la exclusión y la humillación. También es deber del Estado crear leyes y castigar, no solamente las conductas que dañan a terceros, sino también las expresiones que atentan contra la dignidad humana y no favorecen la sana preocupación por los otros. Tal es el caso de Alemania actualmente, en donde se prohíben partidos políticos anti-semitas y publicaciones anti judías, pues esas son expresiones que generan emociones de aversión hacia un grupo o etnia. De hecho se sabe que en la Alemania Nazi había propaganda y discursos explícitos para alimentar el odio, la discriminación y el asco hacia muchos seres humanos considerados indeseables. Hoy la misma historia ha movilizado al pueblo alemán a crear leyes que velen por la dignidad de las personas y limiten la expresión pública de emociones discriminatorias.

El papel del Estado en la sociedad que aspira a la justicia sería entonces, según Nussbaum, el de promover y alentar los principios fundamentales y los ideales constitucionales que permitan la coexistencia de concepciones diversas del sentido y propósito de la vida, fomentando de manera relacionada la defensa de la libre expresión, la libre asociación y la igual dignidad para todos. Todos estos principios que constituyen una sociedad democrática deben impulsarse para que sean parte de las actitudes emocionales de todos los ciudadanos.

Junto a la compasión, como ya se ha mencionado, conviene fomentar también el patriotismo. Pero no la idea de patriotismo negativa y excluyente que invita a definir la nación en contraposición a sus rivales y enemigos exteriores, lo cual sólo agita sentimientos bélicos frente a los demás países, sino el patriotismo que puede servir de puntal necesario para proyectos valiosos que impliquen un sacrificio y amor por los otros (Nussbaum, 2014). Es un sentimiento nacional que puede ayudar a crear una sociedad decente en la que la libertad y la justicia estén verdaderamente al alcance de todos. El patriotismo habla de un nosotros y de lo nuestro, lo cual indica la necesidad de una simpatía extendida. Desde el amor a la nación, las personas pueden adherirse a unos principios políticos generales, pero de una forma que sea además eficaz desde el punto de vista motivacional. Según Nussbaum, "el amor público que necesitamos incluye ese amor por la nación, que es un amor que concibe dicha nación no sólo como un conjunto de principios abstractos, sino como una entidad particular, con una historia específica, unos rasgos físicos concretos y una aspiraciones particulares que inspiran devoción” (Nussbaum, 2014: 251). 
Con la emotividad patriótica se busca devoción y lealtad mediante un relato colorido del pasado de la nación que, normalmente, apunta hacia un futuro que está aún por conocer. Pero ese futuro, según los ideales políticos liberales, implica el reconocimiento de la pluralidad y el respeto por la dignidad humana; dignidad e interés amoroso por los demás seres humanos que vale la pena sostener y que invita a mantenernos unidos frente a las fuerzas poderosas que siempre tratan de resquebrajar este tipo de ideales.

En contraste con este obstáculo al reconocimiento de la dignidad humana, como es la repugnancia según lo expuesto anteriormente, Nussbaum invita a identificar experiencias valiosas que den cuenta de la relevancia ética del cultivo de emociones públicas. El caso de Martin Luther King puede resultar paradigmático al respecto. Cuando el congreso de los Estados Unidos convirtió la fecha del nacimiento de Martin Luther King Jr. en un día festivo nacional, y cuando los líderes y dirigentes de todo el país participan en la celebración de esa festividad, están usando la persuasión para respaldar las normas constitucionales existentes, pero también están alentando la adopción de actitudes emocionales más generales que subyacen a esas normas y están ayudando a que esas leyes y decretos se asienten con mayor firmeza. Las emociones políticas siempre pueden fomentar en los individuos y sociedades la idea de que siempre es tiempo y ocasión para defender la dignidad humana, los derechos, la justicia y la igualdad, que por el hecho de nacer en este mundo poseemos intrínsecamente.

$\mathrm{El}$ arte juega un papel privilegiado en esta noción que propone Nussbaum (2014) de cultivo de emociones públicas: los monumentos también hablan de protección de derechos, de personas frágiles, de igualdad y pluralidad. El arte es un aliado valioso de lo político, a pesar de no haberse explotado suficientemente. La vida pública es pues un terreno de batalla en donde la expresión de las emociones decide en buena parte quienes somos realmente como personas, en qué creemos, cuáles son nuestros principios de vida y hasta qué punto estamos dispuestos a hacer de este planeta un lugar más humano.

\section{Conclusión}

La teoría cognitivo evaluadora de las emociones propuesta por Nussbaum se erige hoy en día como una importante reflexión que aporta nuevas orientaciones al esclarecimiento de la relación entre moral y emociones, al introducir la idea de un juicio endamonista capaz de identificar la presencia de vulnerabilidad, sufrimiento y dignidad humana menoscabada. 
Emociones como la compasión, el amor y la indignación tienen el potencial de advertir sobre los daños morales que pueden causar la repugnancia, el asco y odio que se vuelcan sobre individuos, minorías, discapacitados, determinadas etnias y grupos sociales considerados indeseables.

El análisis de Nussbaum muestra cómo la repugnancia es la cara opuesta de la compasión, y la vergüenza es la reacción contraria a la simpatía extendida y al amor que deberían caracterizar una sociedad liberal decente y justa que reconoce la naturaleza vulnerable del ser humano. La relevancia moral de las emociones como la compasión radica precisamente en que, en sociedades liberales, abiertas, democráticas y pluralistas, como a las que aspira Nussbaum, ésta se erige en un centinela y escudo contra los siempre recurrentes brotes de discriminación, humillación y violencia que estallan como consecuencia de las personas y grupos humanos que se resisten a convivir con las diferencias.

La filosofía de Nussbaum, en este contexto, se levanta como voz que representa las aspiraciones de millones que no cuentan para este sistema dominado por el lucro, la ambición y el deseo de poder de muchos que prefieren la jerarquía, la exclusión y la perpetuación de la injusticia social, porque de alguna manera sienten que no hacen parte de esa naturaleza hecha de piel, sudor, intestinos y lágrimas. En medio de estas realidades oscuras que acechan generando humillación y vergüenza, resulta reconfortante que la filosofía tenga aún mucho que decir sobre el ideal de construir una nueva humanidad en donde todos tengamos el derecho a vivir dignamente, bajo el mismo cielo, pero con diferentes horizontes.

\section{REFERENCIAS}

-Aristóteles (1988). Acerca del alma (T. Calvo, Trad.). Madrid: Gredos. -Aristóteles (1990). Retórica (Q. Racionero, Trad.). Madrid: Gredos. -Aristóteles (2001). Ética Eudemia (J. Pallí, Trad.). Madrid: Gredos. -Aristóteles (2010). Ética Nicomaquea (J. Pallí, Trad.). Madrid: Gredos. -Arnold, M. (1960). Emotion and Personality. New York: Columbia University Press.

-Brentano, F. (1942). Psicología. Buenos Aires: Schpire.

-Brentano, F. (2002). El origen del conocimiento moral. Madrid: Tecnos.

-Cabezas, M. (2014). Ética y emoción. El papel de las emociones en la construcción del juicio moral. Madrid: Plaza y Valdés.

-Calhoun, C. \& Solomon, R. (1989). ¿Qué es una emoción? Lecturas clásicas de psicología filosófica. México: Fondo de Cultura Económica.

-Cornelius, R. (1996). The Science of Emotions. New Jersey: Prentice Hall.

-Davies, O. (2003). A Theology of Compassion. Michigan: Eerdmans Publishing.

-De Waal, F. (1997). Bien natural. Los orígenes del bien y el mal en los bumanos y otros animales. Barcelona: Herder. 
-Ekman, P., \& Davidson, R. (1994). The Nature of Emotions. New York: Oxford University Press.

-Fitzgerald, J. (2008). Passions and Moral Progress in Greco-Roman Thought. New York: Routledge.

-Frijda, N. (1987). Emotions. Cambridge: Cambridge University Press.

-Graver, M. (2007). Stoicism and Emotion. Chicago: The University of Chicago Press.

-Izard, C. E. (1997). Emotions and facial expressions: a perspective from differential emotions theory. En J. A. Russell \& J. M. Fernández-Doll, The Psychology of Facial Expression (pp.57-80). Cambridge University Press.

-Knuuttila, S. (2004). Emotions in Ancient and Medieval Philosophy. New York: Oxford University Press.

-Lazarus, R. (1996). Passion and Reason. Making sense of our emotions. Oxford: Oxford University Press.

-LeDoux, J. (1998). The Emotional Brain. The Mysterious Underpinning of Emotional Life. New York: Simon and Schuster.

-Lyons, W. (1993). Emoción. Barcelona: Anthropos.

-Nussbaum, M. (1995). La fragilidad del bien. Fortuna y ética en la tragedia y la filosofía griega. Madrid: Visor.

-Nussbaum, M. (1996a). Aristotle on Emotions and Rational Persuasion. En A. Rorty (ed.), Aristotle's Rhetoric (pp. 303-323). Berkeley: University of California Press.

-Nussbaum, M. (1996b). Compassion: the basic social emotion. Social Philosopby and Policy, 13(1), 27-58.

-Nussbaum, M. (2003). La terapia del deseo: teoría y práctica en la ética belenística. Barcelona: Paidós.

-Nussbaum, M. (2006). El ocultamiento de lo bumano. Repugnancia, vergüenza y ley. Buenos Aires: Katz.

-Nussbaum, M. (2007). Las fronteras de la justicia. Consideraciones sobre la exclusión. Barcelona: Paidos.

-Nussbaum, M. (2008). Paisajes del pensamiento: la inteligencia de las emociones. Barcelona: Paidós.

-Nussbaum, M. (2012). Crear capacidades. Propuesta para el desarrollo humano. Barcelona: Paidós.

-Nussbaum, M. (2014). Emociones políticas. ¿Por qué el amor es importante para la justicia? Barcelona: Paidós.

-Prinz, J. (2004). Gut reactions. A perceptual theory of emotions. New York: Oxford University Press.

-Solomon, R. (2003). What is an Emotion? Classic and Contemporary Readigns. New York: Oxford University Press.

-Solomon, R. (2004). Thinking about Feeling. Contemporary Philosopher on Emotions. New York: Oxford University Press.

-Trueba, C. (2009). La teoría aristotélica de las emociones. Signos filosóficos, 11(22), 147-170. 
Sumario: Introducción; 1. La tradición estoica en la teoría de las emociones de Nussbaum; 2. Huellas de la teoría aristotélica de las emociones; 3. La influencia de las teorías cognitivas de la emoción en el pensamiento de Nussbaum; 4. La teoría cognitivo-evaluadora de Nussbaum: neoestoicismo, neoaristotelismo y cognitivismo contemporáneo; 5 . El potencial moral de las emociones como advertidoras de daño, sufrimiento y dignidad humana menoscabada; 6. La compasión y la advertencia de sufrimiento; 7 . La repugnancia como limitante de la humanidad compasiva; 8. De lo individual a lo colectivo: el potencial moral de las emociones en la deliberación pública; Conclusión; Referencias. 